\title{
Household level health and socio-economic vulnerabilities and the COVID-19 crisis: An analysis from the UK
}

\author{
Júlia Mikolai ${ }^{1 *}$, Katherine Keenan ${ }^{2 *}$, Hill Kulu ${ }^{3}$ \\ University of St Andrews and ESRC Centre for Population Change, Irvine Building, North Street, St. \\ Andrews, UK, KY16 9AL. \\ ${ }^{1}$ julia.mikolai@st-andrews.ac.uk \\ ${ }^{2}$ katherine.keenan@st-andrews.ac.uk \\ ${ }^{3}$ hill.kulu@st-andrews.ac.uk \\ *Joint first authors.
}

\begin{abstract}
Objectives. To investigate how COVID-19-related health and socio-economic vulnerabilities occur at the household level, and how they are distributed across household types and geographical areas in the United Kingdom.

Design Cross-sectional, nationally representative study.

Setting The United Kingdom.

Participants $\sim 19,400$ households.

Main outcome measures Using multiple household-level indicators and principal components analysis, we derive summary measures representing different dimensions of household vulnerabilities critical during the COVID-19 epidemic: health, employment, housing, financial and digital.

Results Our analysis highlights four key findings. First, although COVID-19 health risks are concentrated in retirement-age households, a substantial proportion of working age households also face these risks. Second, different types of households exhibit different vulnerabilities, with workingage households more likely to face financial, housing and employment precarities, and retirement-age households health and digital vulnerabilities. Third, there are area-level differences in the distribution of household-level -vulnerabilities across England and the constituent countries of the United Kingdom. Fourth, in many households, different dimensions of vulnerabilities intersect; this is especially prevalent among working-age households.

Conclusions The findings imply that the short- and long-term consequences of the COVID-19 crisis are likely to significantly vary by household type. Policy measures that aim to mitigate the health and socio-economic consequences of the COVID-19 pandemic should consider how vulnerabilities cluster together across different household types, and how these may exacerbate already existing inequalities.
\end{abstract}




\section{Summary Box}

\section{What is already known on this topic}

- During the global COVID-19 pandemic, people spend much more time in their immediate households, due to lockdown measures, the need to self-isolate, and school and workplace closures.

- Poor health and socio-economic conditions frequently co-occur at the individual level in the general population.

\section{What this study adds}

- COVID-19-specific health-risks and socio-economic vulnerabilities (financial, housing, digital and employment) co-occur among households in the UK. However, economic vulnerabilities cluster more in working-age households, whereas health and digital vulnerabilities cluster in retirement-age households.

- Policy measures that aim to mitigate the adverse effects of COVID-19 should not only consider health vulnerabilities but also household structure and household-level disadvantages such as poor housing conditions, economic insecurity, and limited access to modern technology.

\section{Introduction}

The COVID-19 global health crisis has led to the widespread introduction of physical distancing measures that keep people in their homes, including household lockdowns, self-isolation for high-risk individuals, and school and workplace closures. As these measures may need to remain in place for some time, this situation leads to concerns over financial, physical and psychological effects as well as potentially widening societal and health inequalities ${ }^{1}$. In the current situation, some household characteristics have become elevated in importance for wellbeing, such as access to a garden or safe outdoor space, technology and internet connectivity, and lack of household crowding, especially because under the given circumstances, these factors cannot be mitigated by interactions with school, work and community contexts ${ }^{2-5}$. Furthermore, global economic slowdown and rising unemployment ${ }^{6}$ may interact with these disparities and exacerbate already existing health and socio-economic inequalities as the pandemic progresses.

Policy advice has so far been oriented towards mitigating individual health risk, without much consideration of how old and young individuals are nested within different household structures and how their opportunities to follow government guidelines might be limited by household and housing characteristics. For example, the UK government has advised 'extremely vulnerable' individuals to shield themselves and self-isolate (often along with their entire household) for a period of 12 weeks, but due to different household situations, this may have radically different implications for how they can protect themselves and organise their lives. We also know from the health inequalities literature that ill health is more common among those suffering other social deprivations, such as poorer housing, overcrowding, financial precarities and social exclusion ${ }^{7}{ }^{8}$. Therefore, self-isolation may negatively impact other dimensions of disadvantage, not only for the 'extremely vulnerable' individuals but also for their household members. A much larger proportion of the population might be considered 'high risk' suffering with chronic conditions that make the chances of COVID-19 complications more likely, such as severe respiratory illnesses. Even in households with no members suffering immediate COVID-19 health vulnerabilities, intersecting social and economic vulnerabilities might exacerbate or contribute to the development of further vulnerabilities over time ${ }^{1}$. Understanding at-risk groups is crucial to be able to prevent a health and socio-economic crises in the short- and long-term. 
In this paper, we investigate household-level health and socio-economic vulnerabilities and how they co-occur across different household types and geographic areas, using cross-sectional data from a nationally representative household survey in the United Kingdom. Our principal aim is to identify intersecting dimensions of household vulnerability, to investigate how they vary by household type and region, and to determine the importance of intersecting vulnerabilities and household structure when mitigating the consequences of the COVID-19 crisis.

\section{Methods}

\section{Data}

We used information from the latest available wave (wave 9) of the UK Household Longitudinal Study ${ }^{9}$ (UKHLS), from 2017-2019, which interviewed approximately 36,000 individuals nested in approximately 20,000 households. We dropped 622 households (3\%) due to missing values on the variables used in the analyses. Our analytical sample consists of 19,425 households $^{\mathrm{a}}$.

\section{Variables}

\section{Indicators of household-level vulnerability}

All vulnerability indicators are calculated at the household-level. For some indicators, information is only available at the individual level. In this case, we have calculated measures at the household-level indicating whether at least one person in the household has a given vulnerability.

We used binary indicators to measure digital and connectivity features of the household: whether the household reported having a home internet connection, and whether they owned a laptop, PC, netbook, tablet, or other type of computer.

Housing conditions were captured through three indicators: whether the household lived in a flat (a proxy for lack of access to outdoor space), whether the accommodation was privately rented, and whether the household lived in overcrowded conditions. Overcrowding was defined as having more than 1 person per room (excluding bathrooms and kitchens) in the dwelling; a measure shown to have equal validity compared with more complex overcrowding metrics ${ }^{10}$.

Employment conditions of the household were captured using three dummy indicators of whether anyone in the household was unemployed, worked part-time, or was employed on a temporary contract.

The financial conditions of the households were measured using two indicators. First, we used a binary variable indicating whether the household reported being in payment arrears (either being behind on paying bills at the time of the interview or having been behind on housing payments in the last 12 months). Second, we created a dummy indicator for households with relative low income defined as households whose net equivalized household income was lower than $60 \%$ of the median net equivalized household income following the definition used by the Department for Work and Pensions ${ }^{11}$.

\footnotetext{
a Of these 19,425 households, $83 \%$ has completed interviews with all eligible household members or provided proxy asnwers for those who did not provide a full interview. Additional analyses (not shown but available upon request) showed that the findings are very similar if we only use information from these households.
} 
We defined two health indicators. First, we derived an individual-level indicator for health conditions indicating a higher risk of COVID-19 complications. In wave 1 of UKHLS (2009-2011) (or in case of new entrants the first time they were interviewed), respondents report if they have ever been doctordiagnosed with a list of health conditions ${ }^{b}$. In subsequent waves, respondents were asked about any new health conditions diagnosed since last interview. Using the current NHS guidance ${ }^{c}$ which provides a list of conditions indicating high risk, we created a binary indicator if the respondent reported ever being diagnosed with any of the following: asthma, congestive heart failure, coronary heart disease, angina, heart attack or myocardial infarction, stroke, emphysema, chronic bronchitis, liver condition, diabetes, cancer, or hypertension). As these are chronic illnesses, we assumed that if an individual reported a condition in a prior wave, the condition also persists to later waves. The prevalence of these individual conditions at the household level is shown in Appendix Table A1. The most common illnesses were hypertension (27\%) and asthma (17\%). To capture those individuals who had more severe versions of these conditions, we combined information from this variable and one which indicates whether individuals suffered from any long-standing physical or mental impairment, illness, or disability. The health indicator variable takes the value of 1 if there is an individual in the household who has ever had any of the listed conditions and who also reported to have a long-standing condition in wave 9. The second health indicator takes the value of 1 if there is an individual in the household who reported that their current job status is 'long-term sick or disabled'.

\section{Household type and area type}

Based on the age of and relationships between household members, we categorised households into five types: single-parent households with children (15 years and under), working-age (below state pension age ${ }^{d}$ ) adult households with children, working-age adult households without children, multigenerational households (i.e. at least one working-age adult and one over state pension age, not necessarily related), and retirement-age households, containing only those who are at least of state pension age.

The area type variable divided UK households into the North of England (North East, North West, Yorkshire and Humber, East and West Midlands), South of England (East of England, South East and South West), London, Wales, Scotland and Northern Ireland.

\section{Analysis}

After describing the distribution of household-level vulnerability indicators and household type, we used principal components analysis (PCA) to establish different dimensions of household vulnerability ${ }^{12}$. PCA has been widely used and validated in the multidimensional poverty literature as a data reduction technique also when analysing a set of binary variables ${ }^{13}$. The number of principal components was selected such that the eigenvalue was larger than 1 for each principal component ${ }^{14}$. After applying promax oblique rotation, ${ }^{e}$ we determined which indicator belongs to which principal component by applying the commonly agreed criteria that the factor loading needs to be above $0.32^{15-}$ ${ }^{17}$. Then, to analyse how different dimensions of vulnerabilities are distributed across household types

\footnotetext{
${ }^{b}$ These conditions are asthma, arthritis, congestive heart failure, coronary heart disease, angina, heart attack or myocardial infarction, stroke, emphysema, hyperthyroidism, hypothyroidism, chronic bronchitis, liver condition, diabetes, cancer or malignancy, epilepsy, hypertension, clinical depression, and in some waves also multiple sclerosis, HIV, and other long standing/chronic condition.

chttps://www.nhs.uk/conditions/coronavirus-covid-19/people-at-higher-risk-from-coronavirus/whos-athigher-risk-from-coronavirus/

'As state pension age varies by respondents' birth year, UKHLS uses information on respondents' age at the time of interview to determine whether they were of state pension age following state pension rules applicable since 6 April 2016.

e Varimax rotation leads to very similar factor loadings and identical principal components.
} 
and different geographical areas, we calculated dummy variables for the top $25 \%$ of the scores on each principal component to indicate households who are most vulnerable on each dimension. All estimates were weighted using cross-sectional household weights.

\section{Results}

First, we describe the indicators used in the analyses. Figure 1 shows the proportion of households who experience different types of vulnerabilities. The most striking finding is that $32 \%$ of households contain at least one individual with a COVID-19 high-risk condition. This was more common in retirement-age and multi-generational households (both 49\%) but ranged between 16 and $26 \%$ in working age households (Appendix Table A2). It was also notable that single-parent households were the most financially precarious: approximately one third experienced payment arrears and low income. (Appendix Table A2). Second, around 23\% of households have at least one individual who is a part-time employee. These households might be at higher risk of COVID-19-induced financial vulnerabilities as they might have fewer savings than households with only full-time employed individuals. Furthermore, between $10-15 \%$ of households live in a flat, live in privately rented dwellings, has no access to the internet, and has no access to a computer, laptop, tablet or netbook in the household. A smaller share of households experience overcrowding (3.5\%), unemployment (5\%) or temporary employment (9\%), have payment arrears (8\%) or contains a person who cannot work due to long-term health conditions or disabilities (6\%).

Figure 1. Proportion of households who experience different types of vulnerabilities

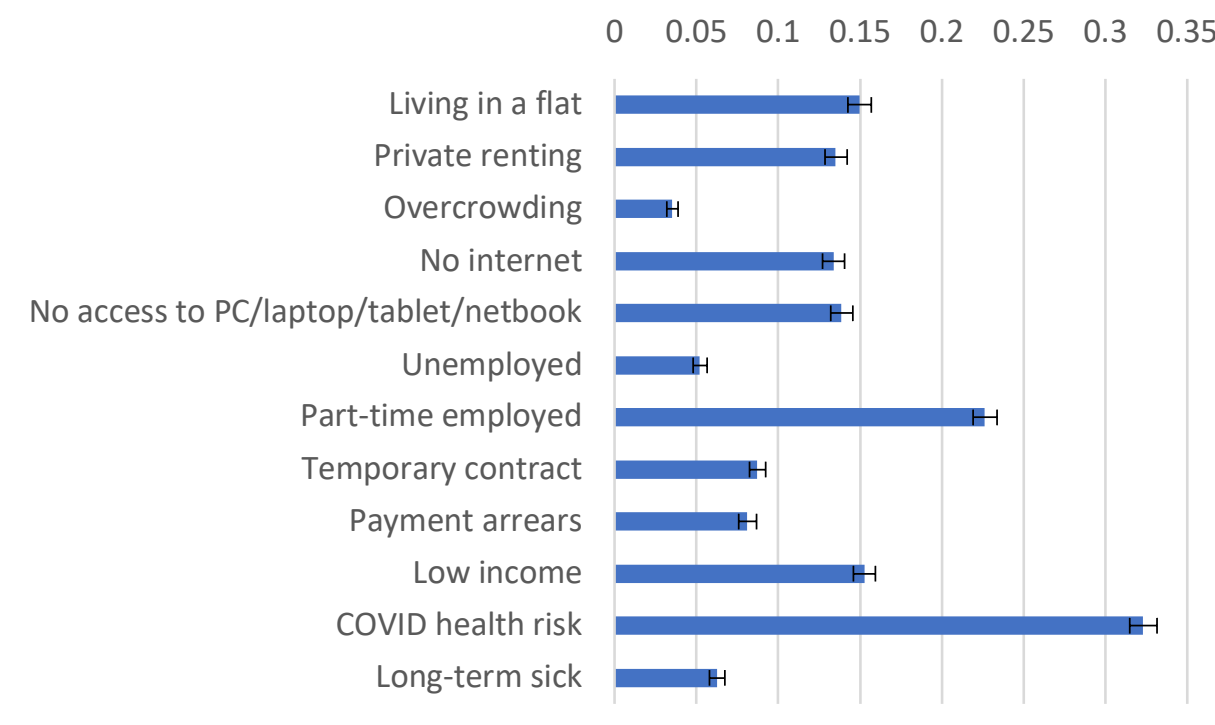

Source: Authors' calculations using data from the UK Household Longitudinal Study, wave 9 (2017/2019). Weighted estimates.

Next, we show the distribution of different types of households (Figure 2). The majority of households in the UK (40\%) are working-age adult households without resident children; the next largest (30\%) type of households are retirement-age households. These are followed by working-age adult households with resident children (18\%), multi-generational households (7\%), and single-parent households (6\%). In terms of household size, almost $60 \%$ of retirement-age households contained one person and living alone was also common among working-age households without children (42\%) (results not shown, but available on request). Table A2 and A3 in the Appendix show how these vulnerability indicators are distributed across different household types and geographic areas, respectively. 
Figure 2. Proportion of different household types in the UK
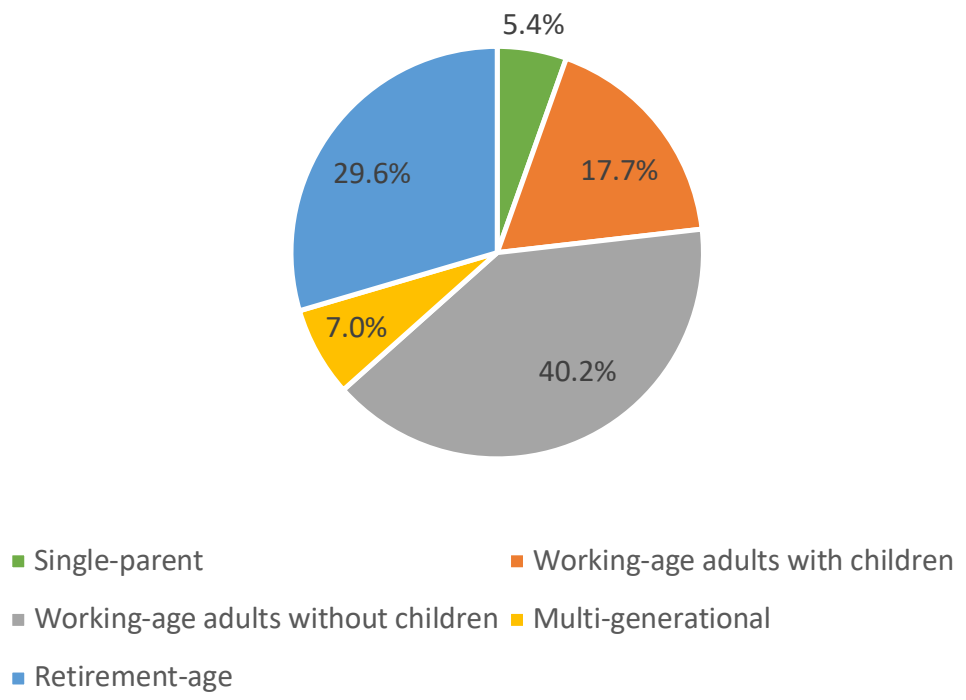

Source: Authors' calculations using data from the UK Household Longitudinal Study, wave 9 (2017/2019). Weighted estimates.

To reduce the number of vulnerability indicators, we used PCA. The results revealed five distinct dimensions of household vulnerabilities (Table 1): digital (access to internet, access to computer), financial (overcrowding, unemployment, low household income, payment arrears), employment (part-time and temporary employment), housing (living in flat and private renting), and health (COVID health risk and long-term illness). In the following parts of the analysis, we use these five dimensions of vulnerabilities and analyse how being in the top quartile (worst off) for these household-level vulnerabilities are distributed across different household types (Figure 3 ) and different geographical areas (Figure 4) of the United Kingdom.

Table 1. Rotated factor scores from Principal Components Analysis

\begin{tabular}{l|ccccc} 
& Digital & Financial & Employment & Housing & Health \\
\hline Living in a flat & 0.109 & -0.081 & -0.042 & $\mathbf{0 . 6 3 3}$ & 0.047 \\
Private renting & -0.044 & -0.083 & -0.034 & $\mathbf{0 . 6 5 9}$ & -0.130 \\
Overcrowding & -0.080 & $\mathbf{0 . 4 0 2}$ & 0.093 & 0.110 & -0.009 \\
Unemployed & -0.046 & $\mathbf{0 . 6 2 6}$ & -0.063 & -0.156 & -0.016 \\
Part-time employed & -0.016 & 0.007 & $\mathbf{0 . 6 8 1}$ & -0.081 & -0.071 \\
Temporary contract & 0.044 & -0.085 & $\mathbf{0 . 7 1 5}$ & 0.008 & 0.025 \\
No internet & $\mathbf{0 . 6 9 0}$ & 0.014 & 0.015 & 0.019 & -0.003 \\
No access to PC/laptop/tablet/netbook & $\mathbf{0 . 6 8 7}$ & 0.026 & 0.017 & 0.032 & 0.001 \\
Low income & 0.151 & $\mathbf{0 . 5 7 8}$ & -0.071 & -0.061 & -0.088 \\
Payment arrears & -0.037 & $\mathbf{0 . 3 2 4}$ & 0.099 & 0.300 & 0.197 \\
COVID health risk & 0.066 & -0.033 & 0.003 & -0.196 & $\mathbf{0 . 6 6 1}$ \\
Long-term sick & -0.054 & -0.032 & -0.038 & 0.077 & $\mathbf{0 . 7 0 6}$ \\
\hline
\end{tabular}

Source: Authors' calculations using data from the UK Household Longitudinal Study, wave 9 (2017/2019).

Note: Boldface indicates factor loadings over 0.32 . 
Figure 3. Proportion of households who experience the most severe vulnerabilities (top $25 \%$ of each principal component score) in different dimensions by household type

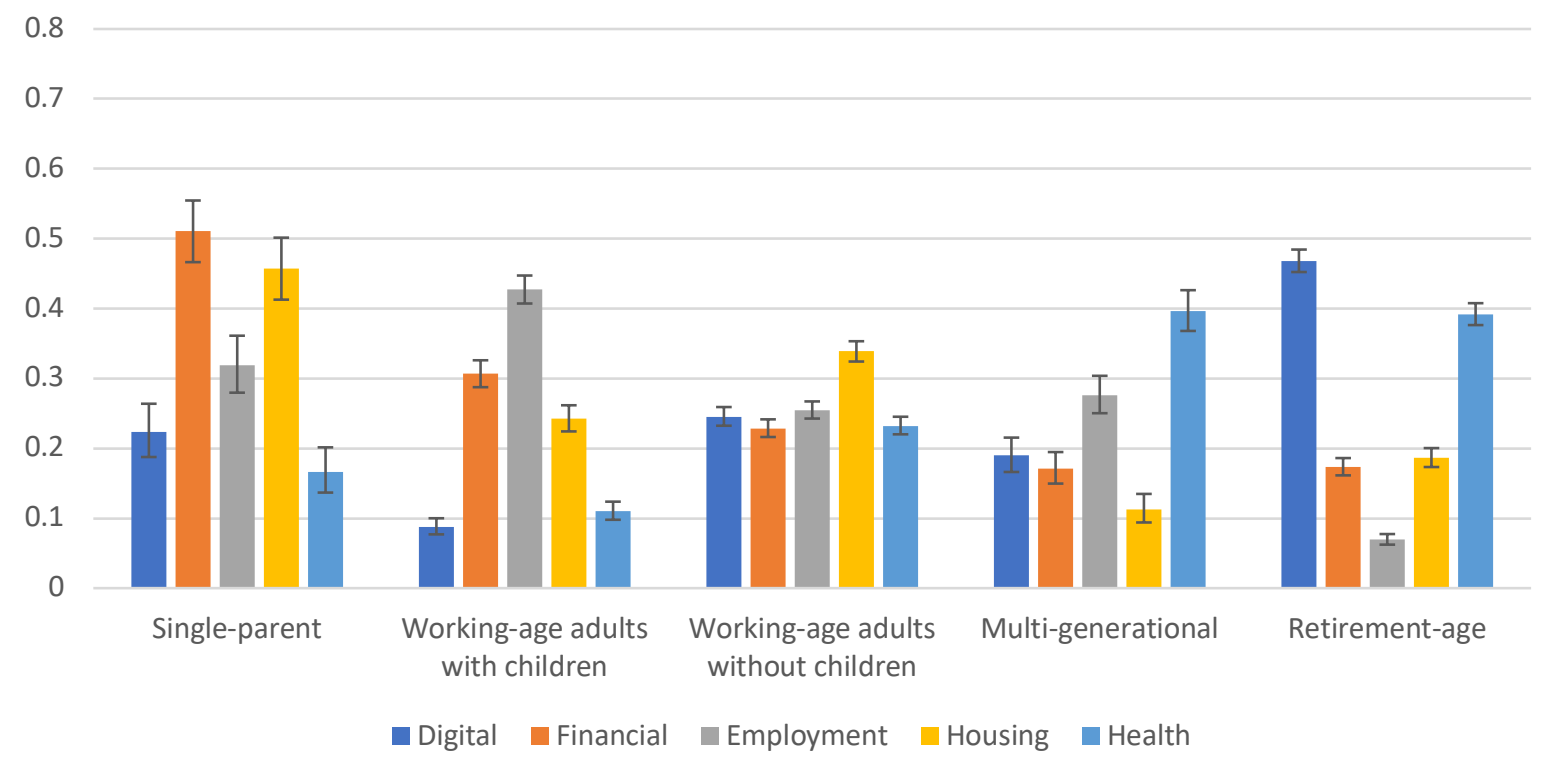

Source: Authors' calculations using data from the UK Household Longitudinal Study, wave 9 (2017/2019). Weighted estimates.

Single-parent households are most likely to experience the most severe financial, housing and employment vulnerabilities (51\%, $46 \%$ and $32 \%$ of single-parent households, respectively). Additionally, $22 \%$ of these households face severe digital vulnerabilities. Working-age adult households with children are most likely to experience severe vulnerabilities for employment (43\%), financial (31\%), and housing (24\%) dimensions. Around $10 \%$ of these households face severe digital and health vulnerabilities. Working-age adult households without children are most likely to experience housing precarities (34\%) (compared with other precarities) and are approximately equally vulnerable on all other dimensions (around 20-25\%). The most commonly experienced vulnerability in multi-generational households is health vulnerabilities (40\%), and a large share of these households also experience severe employment-related disadvantage (28\%). Around $19 \%$ of these households experience severe digital vulnerabilities, $17 \%$ faces financial vulnerabilities and around $10 \%$ severe housing issues. Approximately $40 \%$ of retirement-age households experience severe health vulnerabilities and $47 \%$ digital vulnerabilities, but a large share of them also face severe financial (17\%) and housing (19\%) precarities. 
Figure 4. Proportion of households who experience the most severe vulnerabilities (top 25\% of each principal component score) vulnerabilities in different dimensions by geographical area

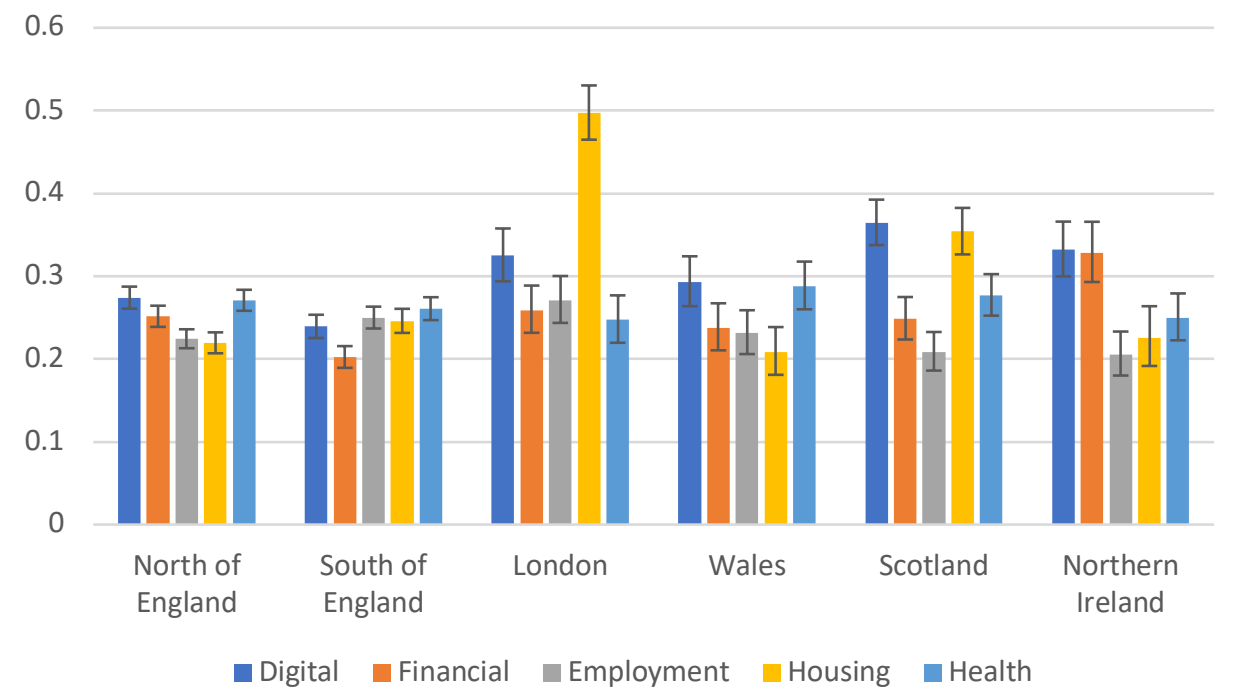

Source: Authors' calculations using data from the UK Household Longitudinal Study, wave 9 (2017/2019). Weighted estimates.

We find some differences in the types of vulnerabilities households experience by geography (Figure 4). Comparing the North and South of England, households in the North experience somewhat higher levels of severe digital, financial, and health vulnerabilities whereas those in the South are somewhat more likely to experience severe housing and employment vulnerabilities. London stands out; households in London are particularly exposed to severe housing and digital vulnerabilities when compared to other areas of England. Households in Wales are very similar to those in England although they experience somewhat higher levels of digital and health vulnerabilities. Households in Scotland are most exposed to severe digital and housing vulnerabilities whereas in Northern Ireland, digital and financial vulnerabilities are the most prevalent.

Many households experience intersecting vulnerabilities (Table 2); this is especially prevalent among working-age households. Among single-parent households, a large proportion (>30\%) of households who face severe health, digital, and employment precarities, also face financial and housing disadvantage and many (54\%) who experience severe financial disadvantage also experience housing precarity. Among working-age households (with and without children), severe health and digital vulnerabilities intersect with financial and housing disadvantage and financial precarities intersect with housing vulnerabilities. In addition, among working-age households without children, severe health vulnerabilities intersect with severe digital vulnerabilities. Intersecting vulnerabilities are somewhat less prevalent among multi-generational and retirement-age households. In both, severe digital vulnerabilities overlap with severe financial disadvantage. In addition, $42 \%$ of retirement-age households who have severe health vulnerabilities also have digital vulnerabilities and $33 \%$ of those who experience digital vulnerabilities also face housing disadvantage. 
Table 2. Proportion of different household types who experience intersecting severe vulnerabilities

\begin{tabular}{|c|c|c|c|c|}
\hline & ital & Employment & Financial & Housing \\
\hline \multicolumn{5}{|c|}{ Single-parent } \\
\hline Health & 0.20 & 0.22 & 0.52 & 0.44 \\
\hline Digital & & 0.09 & 0.78 & 0.46 \\
\hline Employm & & & 0.40 & 0.39 \\
\hline Financial & & & & 0.54 \\
\hline \multicolumn{5}{|c|}{ Working-age adults with children } \\
\hline Health & 0.11 & 0.24 & 0.48 & 0.31 \\
\hline Digital & & 0.26 & 0.76 & 0.35 \\
\hline Employm & & & 0.24 & 0.19 \\
\hline Financial & & & & 0.47 \\
\hline \multicolumn{5}{|c|}{ Working-age adults without children } \\
\hline Health & 0.31 & 0.15 & 0.31 & 0.35 \\
\hline Digital & & 0.15 & 0.50 & 0.58 \\
\hline Employm & & & 0.13 & 0.22 \\
\hline Financial & & & & 0.46 \\
\hline \multicolumn{5}{|c|}{ Multi-generational } \\
\hline Health & 0.19 & 0.14 & 0.13 & 0.09 \\
\hline Digital & & 0.19 & 0.50 & 0.24 \\
\hline Employm & & & 0.11 & 0.12 \\
\hline Financial & & & & 0.19 \\
\hline \multicolumn{5}{|c|}{ Retirement-age } \\
\hline Health & 0.42 & 0.03 & 0.05 & 0.18 \\
\hline Digital & & 0.03 & 0.35 & 0.33 \\
\hline Employm & & & 0.02 & 0.12 \\
\hline Financial & & & & 0.23 \\
\hline
\end{tabular}

Source: Authors' calculations using data from the UK Household Longitudinal Study, wave 9 (2017/2019). Weighted estimates.

Note: The table shows row percentages; for example $20 \%$ of single-parent households who experience severe (top $25 \%$ of principal components scores) health vulnerabilities also experience severe digital inequalities.

\section{Discussion}

Our analysis highlights four key findings. First, while COVID-19 health risks are concentrated in retirement-age households, a substantial proportion (up to $25 \%$ ) of working age households also face these health risks.

Second, we show that all types of households are exposed to multiple, intersecting vulnerabilities. Financial and housing precarity is most prevalent among single-parent households, working-age adult households with children primarily face employment and financial insecurities, whereas their childless counterparts are equally vulnerable on all dimensions. Multi-generational households are likely to experience health and employment vulnerabilities, whereas retirement-age households are characterised by the prevalence of digital and health vulnerabilities. This emphasises that in multigenerational and retirement-age households, health risks co-exist with socio-economic vulnerabilities. This could mean that poor health, or the need to shield, could exacerbate existing financial precarities, 
or indeed that economic necessity could prevent households from self-isolating appropriately. Economic recession for households on the brink financially could worsen physical and social health conditions, thus making people even more vulnerable to the effects of COVID-19. We show that even in households where health-related risks are not as prevalent, different dimensions of socio-economic vulnerabilities co-exist. This highlights the importance of intersecting precarities, which may push vulnerable households towards poorer health outcomes.

Third, there is some variation in vulnerabilities across different areas of England and the constituent countries of the United Kingdom. This indicates that regional approaches may be considered when deciding on how to best mitigate the health and socio-economic consequences of the COVID-19 crisis. However, more spatial disaggregation is necessary to understand regional and neighbourhood-level vulnerabilities.

Fourth, in many households, different dimensions of vulnerabilities intersect. Among all household types and especially among working-age households, all dimensions of vulnerabilities intersect with financial and housing disadvantage. Among working-age households without children and among retirement-age households, severe health vulnerabilities intersect with severe digital disadvantage.

The results highlight the importance of household structure for the potential short- and long-term effects of the COVID-19 crisis. Future policy measures that aim to mitigate the socio-economic and health consequences of the COVID-19 crisis should consider the critical importance of household structure.

Household-level socio-economic and health vulnerabilities are likely to be context-specific, and thus the role of households for moderating inequalities might be more or less relevant in other countries. For example, in Southern Europe with a greater proportion of inter-generational co-residence and contact ${ }^{1819}$, household structure might matter in different ways, by making direct transmission to high risk individuals more likely, for example. Similarly, the types of vulnerabilities that are relevant will vary according to context, and high and low-income settings. In the United States, multidimensional poverty and race intersect at the individual, household and neighbourhood scales. In low income settings, for example, household crowding and mixed generation households might pose serious barriers to the ability to shield elderly and vulnerable people, and these are likely to intersect with other dimensions of poverty ${ }^{20}$. Future studies should compare the importance of different dimensions of vulnerabilities by household type across European as well as low- and middle-income countries.

This study has some limitations. First, we likely underestimate the prevalence of health vulnerabilities as these measures are self-reported and not all members of the household have agreed to be interviewed. Additionally, our disease identification strategy is not specific enough to capture extremely vulnerable individuals who need to shield, because we do not know some of these precise conditions, nor do we know the severity of the conditions included in the analyses. In addition, further work is needed to explore patterns of multimorbidity, including mental health conditions, which are an addititional vulnerability. Future work should repeat this analysis using linked health and administrative data that allow for identifying very high-risk individuals. Second, our analysis is based on data from 2017-19. However, we expect the relationships to be similar in 2020. Taken together, our study suggests that policy measures should take better account of household structure and dynamics for identifying vulnerabilities and advising citizens on how to deal with risk. 


\section{References}

1. Douglas M, Katikireddi SV, Taulbut M, et al. Mitigating the wider health effects of covid-19 pandemic response. The British Medical Journal 2020;369(m1557) doi: 10.1136/bmj.m1557

2. Armitage R, Nellums LB. Considering inequalities in the school closure response to COVID-19. The Lancet Global Health 2020;8(5):e644.

3. Holmes EA, O'Connor RC, Perry VH, et al. Multidisciplinary research priorities for the COVID-19 pandemic: a call for action for mental health science. The Lancet Psychiatry 2020 doi: 10.1016/S2215-0366(20)30168-1

4. Van Lancker W, Parolin Z. COVID-19, school closures, and child poverty: a social crisis in the making. The Lancet Public Health 2020

5. Wang $G$, Zhang $Y$, Zhao J, et al. Mitigate the effects of home confinement on children during the COVID-19 outbreak. The Lancet 2020;395(10228):945-47.

6. Karanikolos M, Mladovsky P, Cylus J, et al. Financial crisis, austerity, and health in Europe. The Lancet 2013 doi: 10.1016/S0140-6736(13)60102-6

7. Sacker A, Ross A, MacLeod CA, et al. Health and social exclusion in older age: evidence from Understanding Society, the UK Household Longitudinal Study. Journaal of Epidemiology and Community Health 2017;71(7):681-90.

8. Marmot M. Health equity in England: the Marmot review 10 years on. The British Medical Journal 2020;368(m693) doi: 10.1136/bmj.m693

9. University of Essex Institute for Social and Economic Research NSR, Kantar Public,. Understanding Society: Waves 1-9, 2009-2018 and Harmonised BHPS: Waves 1-18, 1991-2009. [data collection]. 12th Edition. UK Data Service. SN: 6614, 2019.

10. Cable N, Sacker A. Validating overcrowding measures using the UK Household Longitudinal Study. SSM - Population Health 2019;8(100439)

11. Department for Work and Pensions. Households below average income: An analysis of the UK income distribution: 1994/95-2018/19, 2020.

12. Abdi H, Williams $\mathrm{L}$. Principal component analysis. Wiley Interdisciplinary Reviews: Computational Statistics 2010;2(4):433-59. doi: 10.1002/wics.101

13. Vyas S, Kumaranayake L. Constructing socio-economic status indices: how to use principal components analysis. Health Policy and Planning 2006;21(6)

14. Matsunaga M. How to Factor-Analyze Your Data Right: Do's Don'ts, and How-To's. International Journal of Psychological Research 2010;3(1):97-110.

15. Zwick WR, Velicer WF. Factors influencing four rules for determining the number of components to retain. Multivariate Behavioral Research 1982;17(2):253-69. doi: 10.1207/s15327906mbr1702_5

16. Tabachnick BG, Fidell LS. Using multivariate statistics. Fifth Edition ed: Pearson Education Inc. 2007.

17. Comrey AL, Lee HB. A first course in factor analysis 2 nd edition ed. Hillsdale, NJ: Lawrence Erlbaum Associates 1992.

18. Bayer C, Kuhn M. Intergenerational Ties and Case Fatality Rates: A Cross-Country Analysis. IZA Discussion Paper 2020.

19. Dowd JB, Andriano L, Brazel DM, et al. Demographic science aids in understanding the spread and fatality rates of COVID-19. Proceedings of the National Academy of Sciences 2020 doi: 10.1073/pnas.2004911117

20. Dahab M, van Zandvoort, K., Flasche, S., Warsame, A., Spiegel, P. B., Waldman, R. J., \& Checchi, F. COVID-19 control in low-income settings and displaced populations: what can realistically be done? London: London School of Hygiene and Tropical Medicine, 2020. 


\section{Appendix}

Table A1. Share of different household types who experience the diseases in the Covid-19 health index

\begin{tabular}{|c|c|c|c|c|c|c|c|c|c|c|c|c|}
\hline & \multicolumn{2}{|c|}{ Asthma } & \multicolumn{2}{|c|}{ Heart failure } & \multicolumn{2}{|c|}{ Heart disease } & \multicolumn{2}{|c|}{ Angina } & \multicolumn{2}{|c|}{$\begin{array}{l}\text { Myocardial } \\
\text { Infarction }\end{array}$} & \multicolumn{2}{|l|}{ Stroke } \\
\hline & Proportion & SE & Proportion & SE & Proportion & SE & Proportion & SE & Proportion & SE & Proportion & SE \\
\hline Single-parent & 0.17 & 0.02 & $<0.01$ & 0.00 & $<0.01$ & 0.00 & $<0.01$ & 0.00 & 0 & & $<0.01$ & 0.00 \\
\hline Working-age adults with children & 0.22 & 0.01 & $<0.01$ & 0.00 & $<0.01$ & 0.00 & $<0.01$ & 0.00 & $<0.01$ & 0.00 & $<0.01$ & 0.00 \\
\hline Working-age adults without children & 0.18 & 0.01 & $<0.01$ & 0.00 & 0.02 & 0.00 & 0.02 & 0.00 & $<0.01$ & 0.00 & $<0.01$ & 0.00 \\
\hline Multi-generational & 0.22 & 0.01 & 0.02 & 0.00 & 0.07 & 0.00 & 0.07 & 0.00 & $<0.01$ & 0.00 & 0.01 & 0.00 \\
\hline Retirement-age & 0.13 & 0.01 & 0.03 & 0.00 & 0.08 & 0.00 & 0.08 & 0.00 & 0.01 & 0.00 & $<0.01$ & 0.00 \\
\hline Total & 0.17 & 0.00 & 0.01 & 0.00 & 0.04 & 0.00 & 0.04 & 0.00 & $<0.01$ & 0.00 & $<0.01$ & 0.00 \\
\hline
\end{tabular}

\begin{tabular}{|c|c|c|c|c|c|c|c|c|c|c|c|c|}
\hline & \multicolumn{4}{|c|}{ Chronic } & \multicolumn{2}{|c|}{ Liver condition } & \multicolumn{2}{|l|}{ Cancer } & \multicolumn{2}{|c|}{ Diabetes } & \multicolumn{2}{|c|}{ Hypertension } \\
\hline & Proportion & SE & Proportion & SE & Proportion & SE & Proportion & SE & Proportion & SE & Proportion & SE \\
\hline Single-parent & $<0.01$ & 0.00 & $<0.01$ & 0.00 & 0.03 & 0.01 & $<0.01$ & 0.00 & 0.02 & 0.00 & 0.11 & 0.01 \\
\hline Working-age adults with children & $<0.01$ & 0.00 & $<0.01$ & 0.00 & 0.03 & 0.00 & 0.02 & 0.00 & 0.03 & 0.00 & 0.11 & 0.01 \\
\hline Working-age adults without children & 0.01 & 0.00 & 0.02 & 0.00 & 0.04 & 0.00 & 0.03 & 0.00 & 0.04 & 0.00 & 0.20 & 0.01 \\
\hline Multi-generational & 0.03 & 0.01 & 0.05 & 0.01 & 0.05 & 0.01 & 0.09 & 0.01 & 0.12 & 0.01 & 0.44 & 0.02 \\
\hline Retirement-age & 0.04 & 0.00 & 0.04 & 0.00 & 0.04 & 0.00 & 0.11 & 0.01 & 0.11 & 0.01 & 0.46 & 0.01 \\
\hline Total & 0.02 & 0.00 & 0.02 & 0.00 & 0.03 & 0.00 & 0.05 & 0.00 & 0.06 & 0.00 & 0.27 & 0.00 \\
\hline
\end{tabular}

Source: Authors' calculations using data from the UK Household Longitudinal Study, wave 9 (2017/2019). Weighted estimates. 
Table A2. Share of different household types who experience the analysed vulnerabilities

\begin{tabular}{|c|c|c|c|c|c|c|c|c|c|c|c|c|}
\hline & \multicolumn{2}{|c|}{ Living in a flat } & \multicolumn{2}{|c|}{ Private renting } & \multicolumn{2}{|c|}{ Overcrowding } & \multicolumn{2}{|c|}{ No internet } & \multicolumn{2}{|c|}{ No access to PC } & \multicolumn{2}{|c|}{ Unemployed } \\
\hline & Proportion & SE & Proportion & SE & Proportion & SE & Proportion & SE & Proportion & SE & Proportion & SE \\
\hline Single-parent & 0.15 & 0.02 & 0.28 & 0.02 & 0.06 & 0.01 & 0.05 & 0.01 & 0.06 & 0.01 & 0.11 & 0.02 \\
\hline Working-age adults with children & 0.08 & 0.01 & 0.15 & 0.01 & 0.16 & 0.01 & 0.01 & 0.00 & 0.02 & 0.00 & 0.07 & 0.01 \\
\hline Working-age adults without children & 0.20 & 0.01 & 0.18 & 0.01 & 0.01 & 0.00 & 0.07 & 0.00 & 0.08 & 0.00 & 0.07 & 0.00 \\
\hline Multi-generational & 0.05 & 0.01 & 0.06 & 0.01 & 0.02 & 0.00 & 0.06 & 0.01 & 0.07 & 0.01 & 0.06 & 0.01 \\
\hline \multirow[t]{3}{*}{ Retirement-age } & 0.14 & 0.01 & 0.05 & 0.00 & 0.00 & . & 0.32 & 0.01 & 0.32 & 0.01 & 0.00 & 0.00 \\
\hline & \multicolumn{2}{|c|}{$\begin{array}{l}\text { Part-time } \\
\text { employed }\end{array}$} & \multicolumn{2}{|c|}{$\begin{array}{c}\text { Temporary } \\
\text { contract }\end{array}$} & \multicolumn{2}{|c|}{ Payment arrears } & \multicolumn{2}{|c|}{ Low income } & \multicolumn{2}{|c|}{ COVID health risk } & \multicolumn{2}{|c|}{ Long-term sick } \\
\hline & Proportion & SE & Proportion & SE & Proportion & SE & Proportion & SE & Proportion & SE & Proportion & SE \\
\hline Single-parent & 0.34 & 0.02 & 0.07 & 0.01 & 0.32 & 0.02 & 0.30 & 0.02 & 0.16 & 0.02 & 0.07 & 0.01 \\
\hline Working-age adults with children & 0.42 & 0.01 & 0.12 & 0.01 & 0.11 & 0.01 & 0.12 & 0.01 & 0.17 & 0.01 & 0.03 & 0.00 \\
\hline Working-age adults without children & 0.24 & 0.01 & 0.12 & 0.00 & 0.09 & 0.00 & 0.15 & 0.01 & 0.26 & 0.01 & 0.11 & 0.01 \\
\hline Multi-generational & 0.28 & 0.01 & 0.11 & 0.01 & 0.03 & 0.01 & 0.10 & 0.01 & 0.49 & 0.02 & 0.10 & 0.01 \\
\hline Retirement-age & 0.07 & 0.00 & 0.03 & 0.00 & 0.02 & 0.00 & 0.16 & 0.01 & 0.49 & 0.01 & 0.01 & 0.00 \\
\hline
\end{tabular}

Source: Authors' calculations using data from the UK Household Longitudinal Study, wave 9 (2017/2019). Weighted estimates. 
Table A3. Share of households across different areas who experience the analysed vulnerabilities

\begin{tabular}{|c|c|c|c|c|c|c|c|c|c|c|c|c|}
\hline & \multicolumn{2}{|c|}{ Living in a flat } & \multicolumn{2}{|c|}{ Private renting } & \multicolumn{2}{|l|}{ Overcrowding } & \multirow{2}{*}{$\begin{array}{l}\text { No internet } \\
\text { Proportion }\end{array}$} & \multicolumn{3}{|c|}{ No access to PC } & \multicolumn{2}{|l|}{ Unemployed } \\
\hline & Proportion & SE & Proportion & SE & Proportion & SE & & SE & Proportion & $\mathrm{SE}$ & Proportion & SE \\
\hline South of England & 0.13 & 0.01 & 0.14 & 0.01 & 0.03 & 0.00 & 0.11 & 0.01 & 0.11 & 0.01 & 0.04 & 0.00 \\
\hline Wales & 0.09 & 0.01 & 0.12 & 0.01 & 0.02 & 0.01 & 0.15 & 0.01 & 0.16 & 0.01 & 0.05 & 0.01 \\
\hline Scotland & 0.28 & 0.01 & 0.10 & 0.01 & 0.04 & 0.01 & 0.15 & 0.01 & 0.16 & 0.01 & 0.05 & 0.01 \\
\hline Northern Ireland & 0.05 & 0.01 & 0.16 & 0.02 & 0.04 & 0.01 & 0.21 & 0.01 & 0.26 & 0.02 & 0.08 & 0.01 \\
\hline
\end{tabular}

\begin{tabular}{|c|c|c|c|c|c|c|c|c|c|c|c|c|}
\hline & \multicolumn{2}{|c|}{ Part-time employed } & $\begin{array}{c}\text { Temporary } \\
\text { contract } \\
\text { Proportion }\end{array}$ & \multicolumn{3}{|c|}{ Payment arrears } & Low income & \multicolumn{3}{|c|}{ COVID health risk } & \multicolumn{2}{|l|}{ Long-term sick } \\
\hline North of England & 0.22 & 0.01 & 0.07 & 0.00 & 0.08 & 0.00 & 0.17 & 0.01 & 0.34 & 0.01 & 0.06 & 0.00 \\
\hline London & 0.23 & 0.01 & 0.14 & 0.01 & 0.12 & 0.01 & 0.12 & 0.01 & 0.28 & 0.01 & 0.05 & 0.01 \\
\hline Wales & 0.20 & 0.01 & 0.10 & 0.01 & 0.08 & 0.01 & 0.17 & 0.01 & 0.33 & 0.02 & 0.07 & 0.01 \\
\hline Scotland & 0.21 & 0.01 & 0.08 & 0.01 & 0.07 & 0.01 & 0.17 & 0.01 & 0.30 & 0.01 & 0.08 & 0.01 \\
\hline
\end{tabular}

Source: Authors' calculations using data from the UK Household Longitudinal Study, wave 9 (2017/2019). Weighted estimates. 